\title{
Making Strategic Human Capital Relevant: A Time-Sensitive Opportunity
}

\author{
David Kryscynski \\ Brigham Young University, dk@byu.edu \\ Dave Ulrich \\ The University Of Michigan
}

Follow this and additional works at: https://scholarsarchive.byu.edu/facpub

Part of the Management Information Systems Commons

\section{Original Publication Citation}

Kryscynski, D. \& Ulrich, D., 2015. Making Strategic Human Capital Relevant: A time Sensitive Opportunity. Academy of Management Perspectives. 29 (3): 357-369.

\section{BYU ScholarsArchive Citation}

Kryscynski, David and Ulrich, Dave, "Making Strategic Human Capital Relevant: A Time-Sensitive Opportunity" (2015). Faculty Publications. 1979.

https://scholarsarchive.byu.edu/facpub/1979

This Peer-Reviewed Article is brought to you for free and open access by BYU ScholarsArchive. It has been accepted for inclusion in Faculty Publications by an authorized administrator of BYU ScholarsArchive. For more information, please contact ellen_amatangelo@byu.edu. 


\section{MAKING STRATEGIC HUMAN CAPITAL RELEVANT: A TIME-SENSITIVE OPPORTUNITY}

David Kryscynski (dk@byu.edu), Assistant Professor of Strategy at Brigham Young University’s Marriott School of Management. Professor Kryscynski received his PhD from Emory University’s Goizueta Business school and researches human capital as a source of competitive advantage.

Dave Ulrich (dou@umich.edu) is Rensis Likert Professor of Business, Ross School of Business, University of Michigan. He has a passion for ideas with impact. He has done research and written 30 books and over 200 articles that have shaped three corporate agendas: Effective Leadership, Organization Capabilities, and Human Resources.

\footnotetext{
Abstract

The domain of strategic human capital is emerging at the intersection of strategy and strategic human resource management. Because it is still in the development phase, its core underlying assumptions have not yet solidified. This presents a unique and time-sensitive opportunity to explore and challenge these core assumptions and, specifically, to evaluate whether these assumptions mesh with the lived experiences of practicing managers. We argue that now is the time for the field to ground itself in practical phenomena so that its insights moving forward can be both academically rigorous and practically relevant. In this paper we illustrate the problems of theory for the sake of theory by systematically comparing the assumptions required in firmspecific human capital theory against the lived experiences of workers and managers. We then identify several phenomena that present new and useful opportunities to expand theory in the strategic human capital domain.
} 
Making Strategic Human Capital Relevant - 2

“There is nothing more practical than a good theory.” — Kurt Lewin (Lewin, 1951: 169)

What guidance does the emerging strategic human capital field offer to the manager who wrestles daily with rapidly changing product and labor markets? One of us recently worked with a company that has competed through product innovation for decades but now wants to evolve its strategy from product leadership to customer intimacy. Leaders can articulate this shift, talk about why it matters, define desired outcomes in financial and customer terms, and recommend the actions to make it happen. But within the company they find work patterns and assumptions that are difficult to uncover and even more difficult to change. In other words, the company has a deeply embedded and historical culture of product leadership that may not align with the desire to shift to a new culture of customer intimacy.

As we look to the academic literature both in strategy and in strategic human resource management (SHRM), we find much about HR practices (see Jiang, Lepak, Hu, \& Baer, 2012, for a review and meta-analysis), firm-specific human capital (Hatch \& Dyer, 2004; Wang \& Barney, 2006; Wang, He, \& Mahoney, 2009), and mobility constraints (Campbell, Coff, \& Kryscynski, 2012), but not much about how a company can redirect the actions and behaviors of its critical human capital to deliver on the changing demands of the external marketplace. This is just one example of demanding, practical human capital problems that managers deal with every day but that our academic literature seems to ignore-yet more evidence of the commonly discussed divide between theory and practice (Bartunek \& Rynes, 2014).

Some companies are trying to close the theory-practice gap by reaching out to academicians, who tend to apply traditional academic mindsets rather than bridging mindsets. Here is an example we recently observed: one leading analytics company hired well-trained theorists and 
researchers to help with human capital challenges using the best methods and approaches available in academic research. After considerable effort they developed a model that improved the explained variance in retention at a statistically significant level. But when they shared their results, a thoughtful observer asked, "So how serious is the problem of regrettable losses in the company?” The researchers responded that the company was experiencing less than $2 \%$ regrettable losses for the key positions and top levels, a practically insignificant figure given the other business challenges business leaders face at this company such as global market penetration, product innovation in declining markets, an activist investor trying to strong-arm changes, a culture of silos rather than collaboration, and so forth. The problem is that the academics led their work with theory and assumptions about what was important rather than with questions about the substantive business challenges facing this company. As a consequence, they provided a carefully crafted and rigorous answer to a strategically unimportant question for this particular company.

The emerging domain of strategic human capital has a unique opportunity to engage in research that closes rather than widens the gap between theory and practice. This emerging domain seems to be bringing together scholars and practitioners from two different traditions: strategy and human resource management (Wright, Coff, \& Moliterno, 2014). As with all scholarly domains, strategy and human resources leverage very different assumptions in their approaches to research (Molloy, Ployhart, \& Wright, 2010). These assumptions create both tensions and opportunities for those interested in bringing these two fields together. As scholars from these different traditions merge approaches, these assumptions are naturally challenged, explored, debunked, and extended. Thus, it is likely that the strategic human capital domain will 
emerge with an assumption base that simultaneously extends, borrows, and eliminates assumptions from its two parent traditions.

Also, while scholars carefully work to select appropriate theoretical assumptions, there is a unique and time-sensitive opportunity to evaluate those assumptions against the phenomena of strategic human capital. Specifically, while many scholars are actively engaged in exploring assumptions we have a time-sensitive opportunity to simultaneously check our assumptions against practice. As the field matures and grows into a paradigm, the core assumptions will become taken for granted and difficult to challenge. If the practical phenomena are not carefully integrated now, we may miss the window of opportunity to make this emerging field one that narrows the theory-practice gap and contributes both theory and relevance. As noted above, companies are currently relying more on analytical rigor, but if this rigor comes with traditional academic theory and approach, then companies may find greater insights into less relevant problems. It is important to test the academic assumptions and to evolve them into the world of practice without losing theoretical elegance and research rigor. This way the field can emerge with a set of assumptions that take the best of both theoretical worlds and accurately reflect the experiences of practicing managers striving to realize human capital-based competitive advantages.

We worry, however, that the natural approach of academicians is to meld the assumptions of strategy and HR as primarily a theoretical exercise rather than a merged theory-practice exercise. Specifically, while strategic human capital scholars examine and evaluate which core assumptions to inherit from strategy and which from human resources, we worry that there may not be enough engagement with the phenomena. Assumptions are, by definition, simplifications that allow theorists to abstract away from the inherent heterogeneity in real-life situations. They 
provide the theorist with a convenient ability to explore one key mechanism while holding all other factors constant across units of analysis. The problem is that by starting with assumptions in one theoretical domain and comparing to assumptions in a different theoretical domain, theorists continuously live at least one step removed from managers' lived experiences. As assumptions pile upon assumptions theorists get further and further away from the phenomena and the theories become less and less likely to satisfy Kurt Lewin's definition of "good theory" referenced in the opening quotation.

In addition to failing to provide useful insight to practical managers, theory that is too far removed from the phenomena may lead to policy implications that hurt rather than help competitiveness. We will use firm-specific human capital as an illustrative whipping boy for the broader set of strategic human capital theories, partly because it is so easy to pick on (i.e., lowhanging fruit) but also because one of the authors is deeply steeped in the firm-specific human capital paradigm. We have heard some well-respected scholars discuss the global underinvestment in firm-specific human capital (some comments along these lines may even appear in this special issue) and imply that we need policy changes to shift incentives for individual employees to invest in firm-specific human capital. We believe that such conclusions are based on assumptions that do not mesh with the phenomena. Thus, such policy implications at best may lead to inefficient resource allocation, but at worst could actually damage the global competitiveness of any nation or state that chooses to engage such policies.

Our position is unabashedly normative. We believe that strategic human capital scholars should deeply engage the phenomena they study and look carefully for situations where theories fail to explain reality — that is, scholars should look for what Christensen and Carlisle (2009) called “anomalies.” Doing so may allow strategic human capital scholars to follow in the 
footsteps of intellectual pioneers such as Frederick Taylor, Frank and Lillian Gilbreth, Chester Barnard, and many others who leveraged the complexity of actual phenomena to generate new and useful theories. Starting with assumptions leads to more refined current theories; starting with the phenomenon leads to the creation of innovative new theories. This is a useful time for strategic human capital to discover new conceptual frameworks and assumptions by bridging the theory-practice gap.

We first briefly discuss the theory-practice gap in management research and then describe why the strategic human capital domain is at risk of widening rather than closing this gap. We then describe how delving into the phenomena may help strategic human capital research to close the theory-practice gap. We illustrate this potential by describing several emerging phenomena that we observe in practice and explore the possibilities for strategic human capital scholars to leverage these kinds of phenomena to develop "good theory."

\section{ILLUSTRATING THE THEORY-PRACTICE GAP}

Many have discussed the potential problems of the theory-practice gap in management research (e.g., Bartunek \& Rynes, 2014; Daft \& Lewin, 2008; Rynes, Bartunek, \& Daft, 2001), but we believe the emerging strategic human capital domain has a time-sensitive opportunity to bring theory and practice closer together. The problem, however, is that much of our academic training may actually cause us to drift further from practice rather than closer to it.

Management scholars are well trained in looking for theoretical gaps in the literature. Specifically, doctoral students frequently cut their teeth on comprehensive exam questions that require them to compare and contrast different core theories and identify gaps and tensions between the two. Many times, these gaps arise from disparate and/or conflicting assumptions in 
two theoretical domains. When doctoral students effectively compare theories and identify interesting tensions they are rewarded with passing scores, and the implicit reward reinforces within those students the importance of looking for these kinds of gaps. Rewards for these kinds of interesting theoretical insights remain well into academic careers.

While the ability to identify theoretical tensions may be particularly valuable for generating theoretical insights, examining theoretical tensions devoid of phenomenological grounding risks developing theories that do not mesh with managers' lived experiences. This occurs because theoretical assumptions are, by definition, oversimplifications. In some cases, they are vast oversimplifications. Consider, for example, Becker’s (1964) assumption that wages accurately proxy for the total personal value workers derive from their employment. Becker's purpose was to theoretically explore returns to individuals from investments in firm-specific versus general human capital. The challenges of dealing with worker nonpecuniary preferences and different HR systems within different firms would have significantly distracted from the core purpose of his exploration. In fact, wages/financial gain is only one of many well-documented sources of personal value that employees gain from employment. Thus, he applied a vast oversimplification and clearly acknowledged the limitations of his assumption. As with Becker, theorists benefit greatly from the opportunity to apply theoretical assumptions so that they can focus narrowly on a few theoretical mechanisms and hold all other factors constant, as if they existed in a reality vacuum.

Assumptions like Becker's (1964) are quite useful in pushing theory forward, but they also have downsides. As oversimplifications, assumptions are naturally at least one step removed from managerial experiences. Managers, unlike theorists, do not have the luxury of assuming that all employees have similar and simple motivations or that customers have homogenous 
preferences. Managers must deal with the constant heterogeneity embedded in real organizational life.

When we examine theoretical gaps and tensions between assumptions in different theoretical disciplines, then, we are exploring the tensions between purposeful oversimplifications. When we examine tensions between assumptions, it is possible that resolving those tensions will lead to new theoretical insights that better explain the phenomenon. It is also possible, however, that resolving theoretical tensions can take researchers even further from the phenomenon, widening (or exacerbating) the theory-practice gap that others lament (Rynes et al., 2001).

There are a number of theoretical conversations in the strategic human capital domain that may suffer from the theory-practice gap. As noted above, there is a substantial focus on the antecedents and outcomes of turnover (e.g., Nyberg, 2010; Nyberg \& Ployhart, 2013; Reilly, Nyberg, Maltarich, \& Weller, 2013), but managers are far less concerned with turnover as a phenomenon and far more concerned with retaining the right people at the right times in the right places. Managers clearly worry about regrettable losses, but worry somewhat more about matching the right person to the requirements of the position so that their company can compete in changing market conditions.

We also have substantial research on HR systems (such as performance management, career planning, and learning) and the performance benefits of such systems, but managers are far less concerned about whether their HR systems match the best practices espoused in the research and far more interested in choosing the efficient practices that help them respond to their unique competitive challenges. Do our theories of HR systems provide managers with enough granular insight on how to configure different practices to deliver in idiosyncratic business contexts? For 
example, in our research on HR practices in Asian settings, we found that optimal investments in HR practices vary by strategic focus (e.g., product, customer, or cost) (Ulrich \& Allen, 2014).

There are many such examples where the theoretical conversation seems disconnected from the lived experiences of managers, but for several reasons we choose to focus our detailed discussion on the illustrative example of firm-specific human capital. First, Campbell, Coff, and Kryscynski (2012) recently critiqued firm-specific human capital theory by identifying a number of theoretical conditions required for the theory to inform practice. In other words, they identified a set of implicit assumptions in firm-specific human capital theory that limit the potential explanatory power of the theory in practice. Thus, they provided a nice theoretical bridge to a different type of critique. Second, one of us is deeply steeped in the firm-specific human capital paradigm, so we can address this with detail and authority. We certainly do not mean to suggest that firm-specific human capital theory is representative of all strategic human capital research, but we use this theory to illustrate the potential downsides of continually extending theory based on assumptions without carefully grounding those assumptions in phenomena.

Based on logic from the resource-based view (RBV), firm-specific human capital should be a particularly important strategic resource because it is uniquely valuable in the focal firm. The difficulties with transferring firm-specific human capital to different firms provide theoretical isolating mechanisms that allow the firm to capture quasi-rents (Barney, 1991; Campbell et al., 2012; Rumelt, 1984). The collective wisdom of strategic human capital scholars, then, is that firm-specific human capital is a critically important source of sustainable competitive advantage.

The supposed strategic importance of firm-specific human capital has become so entrenched in modern strategy research that researchers no longer ask whether it is important, but rather 
explore how to create firm-specific human capital given its high taken-for-granted importancethe firm-specific human capital (FSHC) paradox (Wang \& Barney, 2006). The FSHC paradox is that firms need workers to invest in firm-specific human capital, but workers don't want to make these investments (Wang \& Barney, 2006). Workers have a choice about whether to invest in general or firm-specific human capital. If they invest in general human capital they can always take their human capital to another employer and get paid appropriately for their skills. If they invest in firm-specific human capital, they can extract the value from those skills only in their current firm. If the firm goes out of business, if the employees need to change jobs for personal reasons, or if the firm decides to act opportunistically and not compensate the employees for these skills, the employees cannot achieve any reasonable return on their investments. Generally, risk-averse employees are more likely to invest in general human capital, because there is less risk of losing the value of the human capital investment (see Wang and Barney 2006 for a more detailed review of the paradox). The focus on this paradox has led some scholars to claim that we have a global underinvestment in firm-specific human capital that may be holding back our economic growth and development.

Our key concern with the firm-specific human capital paradox is that it rests on a set of assumptions that do not square well with the practical realities of everyday employees or managers. To illustrate this point, we articulate three of these key assumptions and discuss why these assumptions effectively widen the gap between research and practice. 
Making Strategic Human Capital Relevant - 11

\section{Assumption 1: Firm-specific human capital is important for a firm's competitive performance.}

There must be a clear line of sight between unique and difficult-to-transfer employee skills and the firm's ability to continuously outperform competitors in the marketplace. If firm-specific human capital is not substantively important for firm performance, then firms do not need employees to make these investments.

Lazear (2009) suggested that firm-specific human capital is not particularly important in practice. He argued that some of the knowledge that is truly firm specific, such as finding the bathrooms, is important for daily functioning but not particularly relevant for competitive performance. Thus, he proposed that different combinations of general skills may be more practically relevant than trying to search for unique and difficult-to-transfer skills.

Lazear's critiques resonate with us based on our conversations with managers and executives. One of us has spent the past five years engaging practicing managers and executives in conversations about firm-specific human capital. This author has framed questions about firmspecific human capital in language that managers can understand and appreciate. Once it is clear that the practicing managers and executives clearly understand the concept, this author asks about the firm-specific human capital in that particular firm. Without fail, the response is blank stares or confused efforts to converse on the topic.

In one interview a social media software executive was asked what knowledge, skills, and abilities critical employees had that were hard to take elsewhere. He became very animated as he described the unique challenges associated with monetizing social networks and talked about how very specialized those skills were. The author pushed back and suggested that these skills sounded important and relevant to any social media company. This question took the wind out of 
the executive's sails as he then admitted that he was not sure what, if any, knowledge, skills, and abilities his employees had that they could not readily apply at a new job if they moved tomorrow. This same conversation has played out hundreds of times over the last five years in multiple industries with large and small firms and with managers and executives at many different levels of the organization. While managers occasionally acknowledge important firmspecific human capital, the proportion of managers who acknowledge it to those who do not really understand it seems out of balance relative to the significant research attention given to the concept of firm-specific human capital.

We suggest, then, that the very assumption that firm-specific human capital is substantively important for competitive performance may be a convenient oversimplification that draws research attention away from the practical realities faced by managers and executives. Rather than helping us solve practical problems, this assumption serves to widen the gap between research and practice.

In fact, when we talk to managers about competitive advantage without imposing the firmspecific human capital assumptions, their interest starts by figuring out how to meet customer needs better than their competitors in unique ways. They realize that competitors can relatively quickly match financial (competitors match price), strategic (competitors have similar product features), and operational (competitors use similar systems) capabilities (Ulrich \& Lake, 1990; Ulrich, 1993). Managers want to find ways to serve customers in ways that competitors cannot quickly match. Increasingly, they find that this service comes from organizational capabilities, which encompasses talent, leadership, and culture (Ulrich, 1987). Managers want to figure out how to use organization resources to better serve customers and deliver investor results. They are less worried about whether employee skills are specific or general and more worried about how 
employees can create unique value for their customers (Ulrich, Younger, Brockbank, \& Ulrich, 2012). The limiting assumptions of firm-specific human capital do not address the challenge of competitive advantage in ways that inform managerial action.

\section{Assumption 2: Employees must be able to evaluate which investments will yield firm- specific versus general human capital before making those investments.}

In order for employees to choose not to invest in firm-specific human capital, they must be able to tell the difference between investments that yield firm-specific human capital and investments that yield general human capital. If we think carefully about this assumption, we can see that it requires an uncommon level of employee knowledge, awareness, foresight, and ability to process alternatives. We suspect that this assumption fails in practice in several important ways.

First, employees must be able to examine a particular work activity and evaluate beforehand how that activity will add to their human capital portfolios. In other words, they must be able to map a specific work activity to a known set of skills that they will acquire from that activity. This mapping may be clear for a training course with stated learning objectives, but may be less clear for various on-the-job training activities and other more in situ work tasks. We note that this is difficult enough to do in a formal classroom environment, and we rarely encounter individuals in real-world situations who have the foresight and mental mapping abilities to accurately project the skills they will gain from their real-time tasks.

Second, even if employees can map an activity to a specific set of skills, they must also be able to determine the extent to which those skills are transferable and valuable at other firms. This means that employees must be able to map these specific skills to value creation 
opportunities for the current firm and also to project the mapping of those skills to value creation opportunities at other companies. Again, this level of foresight seems unlikely in the typical worker we encounter.

Third, in addition to projecting how these skills will lead to value creation in the current company and in other companies, the employees must be able to predict how the current company and any other potential employers will choose to compensate the employee for those skills.

Again, referring back to our many conversations with employees, managers, and executives, we do not recall ever hearing them describe the dilemma of trying to decide whether to invest in firm-specific or general skills. We have heard discussions about gaining industry expertise and professional expertise, but we have not heard employees talk about the dilemma of gaining skills that are uniquely valuable at the current company. Additionally, in the few instances where we did identify human capital that seemed highly firm specific, we were surprised to find that the employees saw it differently. For example, some employees suggested that even though their actual skills were unique to the company, their underlying ability to acquire those skills could be applied anywhere. They figure that there will be some unique things everywhere and that learning those things is simply par for the course. These comments from employees are consistent with the Morris et al. (2010) argument that firm-specific human capital may be a signal of an employee's more valuable general human capital. They are also consistent with Barnard's (1938) and Simon's (1945) classic notions that employees tend to be willing to do whatever they are asked to do within a reasonable range of requests- that is, any firm-specific human capital investments required may simply fall within an employee’s normal range of willingness. 
Ironically, in all of our combined work we find only one context where Assumption 2 seems to hold in any consistent way: business school faculty. Faculty in business schools seem acutely aware of the benefits of making general investments in their own abilities to publish in top-tier academic journals as opposed to making firm-specific investments in building their own institutions. Thus, they tend to be able to categorize different professional activities as firm specific versus general, and they tend to have reasonably clear understandings of the internal and potential external rewards for those investments. It is possible that we as business school faculty willingly accept these theories because the underlying assumptions match our own professional experiences so well. But it is also likely that our professional experiences are rare exceptions in the broader labor market.

Again, because this assumption seems so disconnected from our experience with employees, managers, and executives (with the exception of business school faculty), we worry that the assumption itself suggests a reality for employees that only rarely exists in practice. Thus, this assumption also seems to widen the gap between research and practice.

\section{Assumption 3: Employees must have discretionary choice over their investments in firm- specific and general human capital.}

The firm-specific human capital paradox also relies on employees having discretionary choice over their human capital investments. If companies can require employees to gain firmspecific human capital in order to keep their jobs, these investments become simply a normal part of the job. They must be able to evaluate their different work tasks and choose the tasks that they prefer based on the level of firm-specific or general human capital that will result. If they do not have this choice, then there is no paradox-employees simply invest because they are 
expected to do so. Lecuona and Reitzig’s (2013) recent work may highlight this issue. They showed that firms with more plant managers who have specific skills may be better positioned to perform. The problem, however, is that plant managers know that they must gain these plantspecific skills in order to do their jobs well. Thus, while the plant-specific skills may be important for effective plant management, we do not anticipate finding any plant managers who refuse to gain this kind of firm-specific human capital or who would require additional compensation above market levels for this job.

In addition to having the freedom to choose, employees also must actually have choices. Many employees are simply not faced with regular opportunities to choose between firm-specific and general human capital. In practice, employees face a series of work tasks that must be completed on a daily basis. Employees take on projects based on assignments, availability, social relationships, personal interest, and/or opportunities for career development—seldom because of the firm-specific human capital they will develop through the project. If all of those daily work tasks are part of gaining firm-specific human capital and none of them are part of gaining general human capital, there is no choice for the employee to make.

One of us has spent the past 30 years working closely with HR executives and business leaders all over the world trying to deeply understand the most important problems they face. In all of those years and literally thousands of interactions, not once has an HR executive or business leader stated that one of the critical problems was figuring out how to motivate employees to make firm-specific investments. Not once did the firm-specific human capital paradox arise. Again, the assumption that employees have discretionary choice may be so constraining that it leads researchers away from the practical realities that employees and managers face. 
Making Strategic Human Capital Relevant - 17

\section{What About Empirical Validation?}

In response to our critiques above an anonymous reviewer posed a very important question: If the assumptions are not well matched to practice, wouldn’t empirical research pick up on this problem through lack of empirical support? There are at least two responses to this insightful question. First, it is possible that the right empirical evidence is not being published. Management scholars [Who?] have a clear bias in the publication process toward publishing papers that either confirm existing theories in new and interesting ways or provide clear evidence contrary to existing theories. The challenge with assumptions is that they oversimplify the world by assuming away heterogeneity. Empirical work that relies on such assumptions may not fully account for the heterogeneity that has been "assumed away.” Real heterogeneity introduces statistical noise in the empirical analyses that may bias researchers against finding statistically significant results. Thus, researchers may run analyses based on these assumptions, not find any significant results, and simply abandon their projects because they get "no results.” Thus, we may simply never see the empirical evidence that challenges the face validity of many theoretical assumptions. This kind of evidence tends to emerge through rich descriptions and interviews rather than through the interpretation of statistical outcomes.

Second, our measures may not always map carefully enough onto the theoretical constructs we hope to study. At the risk of being too critical of one theory, firm-specific human capital also illustrates this problem. For years the most common empirical measure of firm-specific human capital in economics was an individual's tenure in the firm. While tenure certainly proxies for valuable cumulative experience, there is actually very little practical evidence to suggest that firm-specific human capital monotonically increases with tenure. In practice it seems that 
employees learn very quickly what they need to know to be successful in their specific organizations. It may take a few months for employees in simple organizations to figure out the unique ins and outs of the new company and who knows what, etc. In complex companies it may take a year or more. But there is likely a point at which an individual has gained as much firmspecific human capital as she can and there are no additional returns to tenure in firm-specific human capital. Thus, it is not likely that workers continue to gain substantial firm-specific human capital in their 15th, 16th, 17th and later years of employment at the focal firm. Thus, tenure studies may help us learn a great deal about tenure, but probably do not tell us much about firmspecific human capital.

In our own domain scholars have used different measures of firm-specific human capital, but it is not clear that they provide dramatic improvements. He, Wang, and Mahoney (2009), for example, offered a very insightful analysis of how both economic and relationship-based governance mechanisms affect a firm's ability to create and capture value from its knowledge resources. These authors use patent self-citations as a proxy for firm-specific knowledge resources and suggest that these indicate the need for employees to make firm-specific investments in human capital. There are at least two concerns with this empirical approach to measuring firm-specific knowledge resources and firm-specific human capital. First, it is not entirely clear why patent self-citations are appropriate measures of firm-specific knowledge resources. If these knowledge resources are truly firm specific, then why might a firm need to patent them in order to protect them? Patenting seems to be most useful for firms that worry that their knowledge resources are so general that competitors can see them and copy them. The more firm specific the knowledge, the less likely the knowledge can be copied or replicated. Thus, it 
seems that firms are less likely to patent firm-specific knowledge because patenting may provide redundant protections for truly firm-specific knowledge.

Second, the existence of firm-level firm-specific resources does not necessarily imply that individuals must make extreme firm-specific investments. In practice we often find that complex combinations of general resources at the firm level create a firm-specific resource (e.g., Apple’s ability to combine existing technologies into an iPhone). But individual experts in those general resources possess largely general human capital. It is the firm-level combination of those general resources that becomes firm specific. Thus, the existence of firm-level firm-specific knowledge resources does not necessarily imply that the individual workers must make firm-specific human capital investments. We can see, then, that the kind of assumptions we refer to may not be invalidated by our typical empirical analysis, both because the publishing process biases us against ever seeing such disconfirming evidence and because our measures may be too far removed from the theoretical constructs to help us draw meaningful conclusions.

In summary, then, as we examine the firm-specific human capital research, we are left to ask two important questions. First, where is the evidence of the problem? In a field that prides itself on empirical rigor and evidence, we see strikingly little evidence of either the strategic relevance of firm-specific human capital or the firm-specific human capital paradox. Second, and closely related, what is the relevance of the problem? While theorists attempt to create caveats and elegant rationales for firm-specific human capital, managers attempt to find people with skills that will help the organization accomplish its business goals. These skills are more tailored to the strategy of the firm than to the firm itself. An employee who brings creativity, risk taking, and innovation skills will be able to adapt those skills to any number of firms seeking to compete through innovation. Employees who are innovative within one company are equally likely to be 
innovative within another company working to deliver on the same strategy. Managers are concerned about how to recruit the right employees given their strategic goals, how to develop existing employees for future competitiveness, and how to build incentive systems that shape employee behavior in the right direction. These HR practices (recruiting, training, rewarding) are not always to build firm-specific human capital that creates quasi-rent asymmetries, but to find the right technical and social talent to deliver on business goals.

We must honestly ask this question: Do managers know or experience things theorists don't know or appreciate, or do theorists know something managers should know but do not? If the latter, then why have theorists been so unable to help practitioners to understand how to build competitive organizations through human capital? Our opinion on this matter is that theorists have deeply engaged in a conversation that is about theory for the sake of theory, with increasingly simplifying assumptions that disconnect from increasingly complex business realities. We suspect that the firm-specific human capital paradox is a problem in theory but not in practice. Accordingly, continued research exploring this paradox solves a problem that may not actually exist and, more important, renders our field less and less relevant to the practitioners who most need our tools of rigor and insight.

We thus argue that starting with theoretical assumptions and trying to solve problems in theory rather than practice may actually lead researchers further and further away from the practical realities faced by managers. 
Making Strategic Human Capital Relevant - 21

\section{ILLUSTRATING THE OPPORTUNITY TO USE PHENOMENA TO CLOSE THE THEORY-PRACTICE GAP}

As mentioned previously, we believe strategic human capital scholars have an opportunity to strike while the iron is hot and mold the future of strategic human capital research in a way that continuously closes rather than widens the theory-practice gap. Our recommendation for scholars to immerse themselves into their phenomena is certainly not new or novel. The founders of the field of management were simultaneously rooted in both the practice of management and the development of theory. In the late 1800s and early 1900s Frederick Taylor and Frank and Lillian Gilbreth founded "scientific management” based on their observations about how to build efficiency into labor practices and government policies. In 1908, Harvard Business School was started with the hope of making the practice of management an academic discipline. In the 1930s Chester Barnard, president of the New Jersey Telephone Company at the time and an astute observer of management, also tried to bring theory and practice together. On retiring from business, he wrote about the functions of the executive and chaired the Rockefeller Foundation and the National Science Foundation, and also worked to apply theories developed by Talcott Parsons and Max Weber. Peter Drucker, the proclaimed father of modern management, wrote 39 books and thousands of articles about management. He defined himself as a "social ecologist” because his work bridged multiple disciplines (economics, statistics, sociology, psychology) and audiences (academia, business, government, and not-for-profits). He framed issues of corporate decentralization, workers as assets not liabilities, customer centricity, management by objectives, and corporations as a human community.

Many recent scholars have also emphasized the importance of deeply engaging in the phenomenon. We cannot possibly do justice to the volumes that have been said on this topic, but 
we briefly mention three particularly illustrative examples. First, Hackman (1992) described the research experience of Gersick $(1988,1989)$ during her dissertation as an intense engagement with the phenomenon. He mentioned that she was wholly unsatisfied with the current state of theory and would not rest until she deeply understood what was really happening in the teams she was studying. He described the process she used this way:

So one lesson we learn from this research is about the value of staying very close to the phenomena one is studying rather than trying to do scholarly work at arm's length. Bob Grice, an experimental psychologist at the University of Illinois, used to put it this way: “Always handle your own rat.” I tell my own students to "get your hands dirty.” However expressed, the message is the same: if you aspire to breakthrough research, stay insistently close to your phenomena. (p. 75)

Second, Roberto Fernandez uses an excellent framework for academic research that he refers to as "rows and columns.” Rows represent the phenomena and columns represent the disciplines and/or theories. Fernandez gave advice to doctoral students (and others), suggesting that great research occurs at the intersection of rows and columns. Part of his point is that researchers must deeply understand the phenomena they are studying so that they can appropriately leverage those phenomena to inform theory. While we do not want to put words in Fernandez's mouth, we imagine he would support the advice to "handle your own rat."

Third, Christensen and Carlisle (2009) described the importance of deeply immersing into the phenomena in order to accurately describe what is happening, categorize relevant theoretical elements, and then develop hypotheses about correlations between those elements. Their point is that when we deeply immerse ourselves in the phenomena we may uncover anomaliesoccurrences in practice that do not seem consistent with the body of extant theory. Too often researchers ignore anomalies and treat them as noise and/or outliers in their analyses. These 
authors suggest that the anomalies create powerful opportunities to expand theories and, ultimately, help theories tie back to practical problems.

We believe that deeply engaging the phenomena at this time in the emergence of the strategic human capital paradigm will help researchers identify assumptions that will help theoretical advancements remain tightly coupled with practice. We hope that deep engagement will help us to develop "good theory” that makes the strategic human capital domain both theoretically meaningful and practically relevant.

In the spirit of starting with rich descriptions of the phenomenon, let us describe a few recent managerial challenges that could potentially create opportunities for new theory ${ }^{1}$. We do not intend to develop robust theory from these examples, only to illustrate how phenomena like these may help the emerging strategic human capital domain to ground its assumptions in practical realities.

\section{Case 1: Letting Go of Labor Flow}

This case pertains to a global leader in design, manufacturing, distribution, and aftermarket services with more than 200,000 employees around the world, many in emerging markets (China, India, Mexico). They are in a very cost-conscious business in which competitors from lower-wage countries work to manufacture similar products more cheaply as a way to gain market share. To compete, leaders in the company work tirelessly to manage costs while maintaining innovation and customer service. A large part of their costs is labor, so they have focused on increasing productivity. For years, they worked to increase employee retention, particularly in emerging-market operations, assuming that longer-tenured employees would be

\footnotetext{
${ }^{1}$ These examples come from companies we have worked with directly or examples we have encountered in the popular press
} 
more productive. More recently, they have realized that they have institutionalized their hiring process and peaked on learning how to attract, motivate, and retain employees. At their peak ability to retain employees following the best guidance in the modern HR literature, they find themselves hiring about 180,000 employees per year to fill 130,000 manufacturing jobs. Despite their best retention efforts, employees tend to stay an average of six to seven months before moving on.

Company leaders now realize that the next key factor to their competitive success will be managing their culture. They have publicly said, "Culture is the most important sustainable, competitive advantage of any company.” They are looking for ways to build a culture based on capabilities of speed to market (how can we reduce the cycle time from concept to commercialization?), resource mobility (how can we shift our talent from one product or customer to another quickly and cost-effectively?), and collaboration (how can we build longterm collaboration inside the company with teams and outside the company with key customers?). The daunting challenge here is that leaders recognize the importance of culture in a context with exceptionally high turnover that has become the status quo for manufacturing in their region.

We have plenty of rich academic literature exploring the impact of turnover on performance, and in general this literature suggests that there are negative performance implications for very high turnover. But in practice, it is not obvious how this particular company can do more to reduce turnover. More than informing this company that they should reduce their turnover rate (the normative implication from much of the turnover literature), strategic human capital research could explore how companies like this one can embed capabilities into the organization such that turnover becomes less disruptive to the work. 
A potential research question we might explore from this case is this: How can firms realize human capital-based competitive advantages in contexts where the turnover rate is driven more by external market conditions than by firm differences? In these contexts the accumulation and retention of superior talent may be an organizational pipe dream, so the companies that can find ways to get more productivity out of their short-term employees may be the companies that realize the advantages.

\section{Case 2: Organizing to Benefit From Innovation}

This global leader in the consumer electronics industry meets consumer needs by continuously inventing new products and services. They have learned that innovation requires creative and forward-thinking people. They have hired market researchers and even anthropologists who can anticipate future consumer demands and scientists who can create products to meet these demands. They feel that they have the talent for innovation. Their dilemma is how to organize in a way to fully benefit from those innovations. In the past, they have established satellite businesses where innovators can create their new ideas without the bureaucratic overhang of corporate policies. But they have found that the process of innovation starting with idea incubation and moving to the formation of a satellite company has stalled in recent years. Additionally, they are not able to integrate and leverage the insights from these innovative satellite companies into the rest of the organization. The satellite companies are growing but not as fast as they should, and leaders want to know how to organize in ways that maximize the benefit of their innovations.

The innovation challenge is clearly a double-edged sword. If companies keep innovative activities as part of the core operating business, they risk having their bureaucratic policies 
squash innovative solutions before they can get off the ground. If they create innovative opportunities in these satellite companies, it may be too difficult to bring innovations back into the parent company.

A potential research question may be this: How do firms leverage human capital to balance the tension between bureaucratic squashing of internal innovations and resistance to change from external innovations when choosing how to organize? We recently learned of a large consumer finance company that formed a "pirate ship” within the company that simultaneously had internal autonomy to run independently and external authority to drive change in the larger company.

\section{Case 3: Managing Extreme Culture Change}

This case is a leading semiconductor firm with 40 years of experience successfully innovating new products. Despite this success they now want to shift to a new customer base (mobile) and a new focus on services in addition to products. They realize that they have spent years building the existing culture and HR system for their current semiconductor business and their unique position in this established industry. They now need to shift to a new business model with new customers and new work processes.

This brings up several research questions: How does a company manage an extreme cultural shift without losing everything? How does a company integrate a vibrant, fast-paced culture with a new customer base while managing the consistent and reliable culture demanded by the established customer base? As experts at the intersection of humans and strategy, strategic human capital scholars seem uniquely positioned to embrace both the challenges and 
opportunities associated with extreme culture changes and to help develop theory to guide companies facing these realities.

\section{OUR MODEST RECOMMENDATIONS FOR PHENOMENON-BASED THEORY}

One of us has been deeply immersed in the phenomena for more than 30 years, with extensive experience solving human capital challenges in organizations. The other has been deeply immersed in management theories for the past eight years and has been theoretically exploring the natural tensions between assumptions in the traditional strategy and HR literatures. We are both excited about the potential of the emerging domain of strategic human capital at the intersection of strategy and HR. We are deeply worried, however, by the possibility that academic researchers will focus on theoretical tensions without carefully grounding their theoretical assumptions in the modern phenomenon we study.

To be very frank, I (the author who is deeply immersed in academic research) write this article as a hypocrite. As I evaluate my own research I find several core theoretical arguments that create interesting theoretical contributions but do not pass the sniff test in practice. These arguments pass the academic sniff test by effectively identifying assumptions and/or theories in tension, but practicing managers would not relate to the phenomena I describe theoretically in some of these articles. Thus, I must ask myself this very honest question: Am I furthering the work of the strategic human capital domain, or am I helping to pull us further from the population we are ultimately tasked to serve and help?

To also be very frank, I (the author with 30 years of experience straddling theory and practice) write this article with real concern. Managers are often lured by the newest, shiniest toy (in this case popular or new management practice). They implement the new management 
practice with good intent, but lack a thorough understanding of why, when, or how the new toy really works. Absent rigorous theory, management best practice is isolated and illusionary. Practice needs theory to test ideas that cumulate knowledge.

Thus, we offer a few modest recommendations to help strategic human capital scholars move research forward in ways that help to close the gap between theory and practice. First, tie theoretical explanations to observable phenomena. Scholars can start with an interesting phenomenon and then use theoretical tools to help explain it, or scholars can start with a theoretical explanation and then carefully evaluate that explanation against the phenomenon. This is, after all, what the founders of management theory did. The Taylors, Barnards, Gilbreths, and Druckers of the world had real practical experience with the lived phenomena of management. Their experiences led each of them to engage theoretical descriptions of themes and patterns in ways that would improve managerial decision making.

We are certainly not suggesting that all strategic human capital scholars abandon their wellhoned skills in theory development and deductive reasoning and dive deeply into case studies. Such a recommendation is not only extreme and unrealistic, but also sacrifices the great rigor and discipline that we bring to the domain. Instead, we suggest that we would each benefit from playing in the phenomenological sandbox and exploring new theoretical opportunities. Specifically, as we identify the core assumptions of our theories, we may benefit by asking thoughtful practicing managers whether those assumptions pass the sniff test in practice, and we may read one or more practitioner books that illustrate the lived experiences of managers in that particular area. We may also choose to listen carefully to the challenges managers face and try to understand the questions they are trying to answer. Managers want to provide rigorous and thoughtful responses to the business challenges they face. If and when academics can engage in 
the phenomena in appropriate ways, they can bring new insights to both management and theory. Thus, while we do not propose that all academic research in this domain be grounded theory, we do suggest that strategic human capital research has a unique opportunity to grow tightly coupled to practice.

Second, carefully evaluate the matching between the relevant theories and the phenomenon. Do the standard explicit and implicit assumptions in the theories match the phenomena they purport to explain? Do the assumptions help to understand the phenomena, or do they simplify the phenomena so much that insights are too far removed from managers' lived experiences?

Third, look for opportunities to challenge or relax assumptions based on what you observe in the phenomenon. If an assumption is too constraining and/or too far removed from the phenomenon, there may be an opportunity to enrich theory by bringing it closer to practice, effectively enhancing the explanatory power of the theory.

Fourth, develop new insights that explain what happens when those assumptions are relaxed or modified. Draw upon both observations from the phenomenon and theoretical insights from related theories to generate new and more nuanced explanations for the phenomenon.

Fifth, test these new modified theories to see if the new theory is both relevant and generalizable.

\section{CONCLUSION}

While our suggestions to bring theory closer to practice are in no way new, our commentary focuses on the emerging field of strategic human capital. We see this field beginning to build momentum, and we believe that it has great potential both on its academic merit and on its potential to provide meaningful and practical insights to managers struggling to make decisions 
about human capital issues. The problem, however, is that pursuing theory for the sake of theory could take this field further and further away from practice and, unfortunately, render it irrelevant to the broader business community. This is the time for scholars to carefully engage the phenomena they study and work to align their theories and assumptions with the practical realities managers face. If we do this well, this emerging field may provide both academic rigor and practical insight. We hope that the field chooses to close, rather than widen, the theorypractice gap. 
Making Strategic Human Capital Relevant - 31

\section{REFERENCES}

Barnard, C. I. (1938). The functions of the executive. Cambridge, Mass., Harvard U. P.

Barney, J. B. (1991). Firm resources and sustained competitive advantage. Journal of Management, 17, 99-120.

Bartunek, J., \& Rynes, S. (2014). Academics and Practitioners Are Alike and Unlike The Paradoxes of Academic-Practitioner Relationships. Journal of Management. Retrieved from http://jom.sagepub.com/content/early/2014/04/08/0149206314529160.abstract

Becker, G. (1964). Human capital: A theoretical and empirical analysis, with special reference to education. University of Chicago Press.

Campbell, B. A., Coff, R. W., \& Kryscynski, D. G. (2012). Rethinking Sustained Competitive Advantage from Human Capital. Academy of Management Review, 37(3).

Christensen, C., \& Carlile, P. (2009). Course research: Using the case method to build and teach management theory. Academy of Management Learning \& .... Retrieved from http://amle.aom.org/content/8/2/240

Daft, R., \& Lewin, A. (2008). Perspective-Rigor and Relevance in Organization Studies: Idea Migration and Academic Journal Evolution. Organization Science. Retrieved from http://pubsonline.informs.org/doi/abs/10.1287/orsc.1070.0346

Gersick, C. J. G. (1988). Time and transition in work teams: Toward a model of new group development. Academy of Management Journal, 31(1), 9-41.

Gersick, C. J. G. (1989). MARKING TIME: PREDICTABLE TRANSITIONS IN TASK GROUPS. Academy of Management Journal, 32(2), 274-309. Retrieved from http://search.ebscohost.com/login.aspx?direct=true\&db=bth\&AN=4405953\&site=bsi-live

Hackman, J. (1992). Time and transitions. In P. J. Frost \& R. E. Stablein (Eds.), Doing exemplary research (pp. 73-78). Sage. Retrieved from http://scholar.harvard.edu/rhackman/publications/time-and-transitions

Hatch, N. W., \& Dyer, J. H. (2004). Human capital and learning as a source of sustainable competitive advantage. Strategic Management Journal, 25(12).

Jiang, K., Lepak, D. P., Hu, J., \& Baer, J. C. (2012). How Does Human Resource Management Influence Organizational Outcomes? A Meta-analytic Investigation of Mediating Mechanisms. Academy of Management Journal, 55(6), 1264-1294. doi:10.5465/amj.2011.0088

Lazear, E. P. (2009). Firm-specific human capital: A skill-weights approach. The Journal of Political Economy, 117(5), 914. 
Making Strategic Human Capital Relevant - 32

Lecuona, J., \& Reitzig, M. (2013). Knowledge worth having in "excess”: The value of tacit and firm-specific human resource slack. Strategic Management Journal. Retrieved from http://onlinelibrary.wiley.com/doi/10.1002/smj.2143/full

Lewin, K. (1951). Field theory in social science: selected theoretical papers (Edited by Dorwin Cartwright.). Retrieved from http://psycnet.apa.org/psycinfo/1951-06769-000

Molloy, J. C., Ployhart, R. E., \& Wright, P. M. (2010). The Myth of “the” Micro-Macro Divide: Bridging System-Level and Disciplinary Divides. Journal of Management, 37(2), 581-609. doi:10.1177/0149206310365000

Morris, S., Alvarez, S., Barney, J. B., \& Molloy, J. (2010). Employee Investments in FirmSpecific Human Capital and Firm Level Competitive Advantage. Working Manuscript.

Nyberg, A. (2010). Retaining your high performers: Moderators of the performance-job satisfaction-voluntary turnover relationship. Journal of Applied Psychology. Retrieved from http://psycnet.apa.org/journals/apl/95/3/440/

Nyberg, A., \& Ployhart, R. (2013). Context-emergent turnover (CET) theory: A theory of collective turnover. Academy of Management Review. Retrieved from http://amr.aom.org/content/38/1/109.short

Reilly, G., Nyberg, A., Maltarich, M., \& Weller, I. (2013). Human capital flows: Using contextemergent turnover (CET) theory to explore the process by which turnover, hiring, and job demands affect patient satisfaction. Academy of Management .... Retrieved from http://amj.aom.org/content/early/2013/04/25/amj.2012.0132.short

Rumelt, R. P. (1984). Towards a strategic theory of the firm (pp. 556-570). Englewood Cliffs, NJ: Prentice-Hall.

Rynes, S., Bartunek, J., \& Daft, R. (2001). Across the great divide: Knowledge creation and transfer between practitioners and academics. Academy of Management Journal. Retrieved from http://amj.aom.org/content/44/2/340.short

Simon, H. (1945). Administrative Behavior. New York.

Ulrich, D. (1987). Organizational capability as a competitive advantage: Human resource professionals as strategic partners. Human Resource Planning, 10(4), 169-180.

Ulrich, D. (1993). Profiling Organizational Competitiveness Cultivating Capabilities. Human Resource Planning, 16(3), 1-17.

Ulrich, D., \& Allen, J. (2014). Talent Accelerator Understanding How Talent Delivers Performance for Asian Firms. South Asian Journal of Human Resources .... Retrieved from http://hrm.sagepub.com/content/1/1/1.short 
Ulrich, D., \& Lake, D. (1990). Organizational capability: Competing from the inside out. New York: Wiley.

Ulrich, D., Younger, J., Brockbank, W., \& Ulrich, M. (2012). HR from the outside in. New York: McGraw.

Wang, H. C., \& Barney, J. B. (2006). Employee incentives to make firm-specific investments: Implications for resource-based theories of corporate diversification. Academy of Management Review, 31(2), 466-476.

Wang, H. C., He, J., \& Mahoney, J. (2009). Firm-specific knowledge resources and competitive advantage: The roles of economic- and relationship-based employee governance mechanisms. Strategic Management Journal, 30(12), 1265-1285. doi:10.1002/smj.787

Wright, P., Coff, R., \& Moliterno, T. (2014). Strategic Human Capital Crossing the Great Divide. Journal of Management. Retrieved from http://jom.sagepub.com/content/40/2/353.short 